\title{
Effects of repeated superovulation and surgical oocyte collection on ovarian response and natural breeding ability of the tammar wallaby (Macropus eugenii)
}

\author{
G. M. Magarey, J. C. Rodger, J. M. Buist and K. E. Mate* \\ Cooperative Research Centre for Conservation and Management of Marsupials, Department of Biological \\ Sciences, Macquarie University, NSW 2109, Australia
}

The aim of this study was to assess the response of a marsupial, the tammar wallaby (Macropus eugenii) to repeated superovulation and surgical oocyte collection and monitor any effects on subsequent natural breeding ability. Animals ( $n=5$ per group) were superovulated once, twice or three times with pig FSH (pFSH; 6 mg administered twice per day for 4 days) followed by $4 \mathrm{mg}$ pig LH (pLH). There was an interval of either 5-6 weeks $(n=9)$ or 12 weeks $(n=1)$ between the first and second superovulation and $13-17$ weeks $(n=5)$ between the second and third superovulation. Oocytes were collected surgically after each treatment. Serum was collected at the time of each treatment to monitor the formation of anti-pFSH and anti-pLH antibodies. Animals were allowed to mate naturally in the season following superovulation treatment(s). There was no significant difference between groups in the number of large follicles (2-5 $\mathrm{mm}$ diameter, mean \pm standard error) produced in response to the first $(21.2 \pm 4.3)$, second $(\mathbf{1 8 . 0} \pm \mathbf{6 . 5})$ or third $(29.0 \pm 4.9)$ superovulation treatment. Eggs were recovered from approximately $80 \%$ of follicles that were flushed during laparotomy. There were significant concentrations of anti-pFSH and anti-pLH antibodies $(P<0.05)$ detected in previously superovulated animals at the time of the second superovulation but not at the time of the third superovulation. The antigonadotrophin antibodies present at the time of repeated superovulation did not cause a significant decrease in average number of follicles. All animals produced pouch young in the breeding seasons after repeated superovulation. Combined with other reproductive technologies, repeated superovulation has the potential to increase the production of offspring from rare or valuable marsupials in captivity.

\section{Introduction}

Assisted reproductive technologies are complex but increasingly important tools that can be applied to conservation (Rodger 1990; Holt and Pickard, 1999; Wildt et al., 2001). Successful application involves investigation and modification of each technology to suit the unique reproductive physiology of the target species, which is largely unknown for most threatened marsupials.

The tammar wallaby (Macropus eugenii) is an established marsupial model and has therefore been used to develop a number of reproductive technologies including superovulation (Molinia et al., 1998a), sperm cryopreservation (Molinia and Rodger, 1996; Taggart et al., 1996), artificial insemination (Molinia et al., 1998b; Johnston and Holt, 2001) and oocyte maturation (Mate and Rodger, 1993). Superovulation is a critically important technology for the tammar wallaby as it is

*Correspondence

Email: kmate@possum.bio.mq.edu.au naturally monovular and highly seasonal, with breeding restricted to the period of decreasing daylength between the summer and winter solstices (reviewed by Hinds et al., 1990). Superovulation protocols have been developed for several other marsupials (Rodger and Mate, 1988; Rodger et al., 1992; Hickford et al., 2001), primarily as research tools. The repeatability and subsequent effects of superovulation on the donor have not been addressed in any marsupial, as oocytes or embryos are usually collected from animals during experimental studies. As repeated superovulation and oocyte collection potentially play a pivotal role in marsupial assisted breeding programmes, it is critical that they do not affect the future natural breeding ability of valuable animals.

Laparoscopic oocyte collection after superovulation has been performed in the brushtail possum (Trichosurus vulpecula; Mate et al., 1992). However, details such as oocyte collection rate and subsequent fertility were not reported. Collection of follicular oocytes by laparoscopy or laparotomy is well established in many eutherian species including numerous ungulates (Loskutoff et al., 
1995; Tervit, 1996; Bainbridge et al., 1999), cats (Goodrowe et al., 1988; Miller et al., 1990) and primates (Kuehl and Dukelow, 1979; Bavister et al., 1984). Repeated oocyte collection has also been performed laparoscopically or transvaginally with ultrasound guidance in several ungulate species (Pieterse et al., 1988; Kuhholzer et al., 1997; Graff et al., 1999). These methods of repeated oocyte collection do not appear to have any detrimental effects on the subsequent reproductive potential of domestic species (Broadbent et al., 1997; Stangl et al., 1999). Superovulation and ultrasound-guided transvaginal follicle aspirations are also repeatedly performed in human in vitro fertilization clinics without significant risk to future fertility (Sauer, 1996).

Although superovulation has been repeated successfully in several eutherian species, the use of exogenous hormones derived from a different species can generate anti-gonadotrophin antibodies and reduced ovarian response to subsequent treatment. These effects have been reported in the domestic cat (Swanson et al., 1995, 1996), rhesus monkey (Bavister et al., 1986; Iliff et al., 1995) and goat (Remy et al., 1991; Roy et al., 1999). Although pig-derived gonadotrophin hormones are effective at inducing follicular stimulation and ovulation in the tammar wallaby (Molinia et al., 1998a), they may also stimulate an immune response and affect future fertility.

The aim of this study was to assess the response of the tammar wallaby to repeated superovulation and surgical oocyte collection. More specifically, the issues addressed were: (1) Does the ovary respond equally to successive superovulation treatments? (2) What is the oocyte collection rate after surgical follicle aspiration? (3) Are antibodies produced against the superovulatory hormones and do they reduce the response to subsequent superovulation? and (4) Does repeated superovulation and surgical oocyte collection affect subsequent natural breeding ability?

\section{Materials and Methods}

\section{Animals}

Tammar wallabies (Macropus eugenii) were used from the colony at the Macquarie University Fauna Park. They were housed in outside yards and fed a diet of kangaroo pellets and lucerne hay (Mate et al., 1999). Adult females over 2 years of age and of proven reproductive ability were used in this study. They had no previous exposure to exogenous gonadotrophins nor any earlier surgical procedures and remained clinically healthy throughout the duration of the experiment. Animal experimentation had the approval of NSW National Parks and Wildlife Service, and the Animal Ethics Committee at Macquarie University.

\section{Superovulation}

Follicular development was induced with $6 \mathrm{mg}$ pig FSH (pFSH) (Folltropin-V; Vetrepharm, Ontario) administered i.m. twice per day at $12 \mathrm{~h}$ intervals for 4 days. Oocyte maturation was induced with a subcutaneous injection of $4 \mathrm{mg}$ pig LH (pLH) (Lutropin-V; Vetrepharm) $12 \mathrm{~h}$ after the last pFSH injection (Molinia et al., 1998a). This protocol induces superovulation of a similar number of eggs in both cyclic and non-cyclic wallabies throughout the year (Molinia et al., 1998a).

Animals ( $n=5$ per group) were superovulated one (group S1), two (group S2) or three (group S3) times. Oocytes were retrieved surgically from each animal approximately $24 \mathrm{~h}$ after pLH administration, as described below. The interval between the first and second superovulation was either $5-6$ weeks $(n=4$ in S2; $n=5$ in S3) or 12 weeks ( $n=1$ in S2). The interval between the second and third superovulation was extended to 1317 weeks ( $n=5$ in S3), because of the presence of large cystic follicles (in addition to normal follicles) at the time of the second oocyte collection and the death of four wallabies early in the course of the experiment. It was considered that allowing a longer recovery interval may reduce stress and the risk of associated complications.

\section{Surgical oocyte collection}

Animals received prophylactic procaine penicillin (15 mg Benacillin kg-1 i.m.; Troy Laboratories, Smithfield) before surgery. Atropine sulphate (0.05 mg Atrosite $\mathrm{kg}^{-1}$ i.m.; Troy Laboratories) was administered during surgery, if required, to reduce brachycardia or excessive salivary secretions. General anaesthesia was induced with $5 \%$ isoflurane (Isoflo; Abbot Australia, Cronulla) delivered via a T-piece and facemask in oxygen at a flow rate of $1.5 \mathrm{I}$ per min. When an adequate depth of anaesthesia was achieved, a cuffed endotracheal tube (size 4 or $3.5 \mathrm{~mm}$ ) was inserted into the trachea and anaesthesia was maintained with $1.5-3 \%$ isoflurane.

After stabilization of general anaesthesia, wallabies were placed in dorsal recumbency with heads tilted to an angle of $30^{\circ}$ using an adjustable surgical table to improve access to the reproductive tract. Standard aseptic techniques were used throughout the procedure. The surgical site was prepared and the long acting local anaesthetic bupivicane hydrochloride (1 mg Bupivicane $\mathrm{kg}^{-1}$ injection B.P. 0.5\%; Delta West, Pharmacia Australia, Bentley) was administered at the incision site for post-operative pain management. When a permanently attached pouch young was present, a $3 \mathrm{~cm}$ laparotomy incision was made lateral to the pouch opening, at the cranial end of the epipubic bone. If there was no pouch young (or the pouch young could be removed for the duration of the surgery), a $3 \mathrm{~cm}$ midline laparotomy incision was made inside the pouch, midway between the teats and the cranial pouch border. 
Each ovary was exteriorized using a spay hook and examined for extent of follicular stimulation and any abnormalities such as cysts or adhesions. Follicles of $2 \mathrm{~mm}$ in diameter or greater were flushed and aspirated using an 18-gauge double-lumen needle (Cook Australia, Eight Mile Plains) connected to a V-MAR-5100 regulated vacuum pump (Cook) that applied a suction of 80$100 \mathrm{~mm} \mathrm{Hg}$, and a V-MAR-4000 flushing system (Cook). The number of large follicles aspirated on each ovary was recorded. A minimum follicle diameter of $2 \mathrm{~mm}$ was chosen for aspiration as at least $60 \%$ of follicles of this size or larger contain mature eggs (G. Magarey and K. Mate, unpublished). Each follicle was flushed at a rate of $0.15 \mathrm{ml} \mathrm{s}{ }^{-1}$ with warm Dulbecco's modification of Eagle's medium (DMEM; Trace Biosciences, Hamilton) supplemented with $12.5 \mathrm{iu}$ heparin $\mathrm{ml}^{-1}, 2.5 \%(\mathrm{v} / \mathrm{v})$ fetal calf serum, 100 iu penicillin $\mathrm{ml}^{-1}$ and $100 \mu \mathrm{g}$ streptomycin $\mathrm{ml}^{-1}$. The flushings were collected in a $12 \mathrm{ml}$ culture tube held at $36^{\circ} \mathrm{C}$ in a Lec 960 portable incubator (Lec Instruments, Victoria).

Small follicles $(0.5-1.9 \mathrm{~mm})$ were pricked with a 26-gauge needle before the ovary was returned to the abdomen to minimize the risk of cyst formation (performed after the second and third treatments only). The analgesic carprofen (4 mg Rimadyl kg ${ }^{-1}$ s.c.; Pfizer, West Ryde) was administered during wound closure.

\section{Assessment of eggs}

Eggs were located in the follicular flushings using a dissecting microscope and the number collected from each ovary was recorded. The nuclear maturation status of eggs was assessed by the presence or absence of a polar body using an inverted microscope (Zeiss Axiovert 35, Germany) with modulation contrast optics (Hoffman, New York).

\section{Detection of anti-pFSH and anti-pLH antibodies}

Blood samples $(5 \mathrm{ml})$ were collected from unsedated restrained animals via a lateral tail vein using a 21-gauge butterfly needle before each superovulation and at other opportunistic times after superovulation. Blood was allowed to clot at $4^{\circ} \mathrm{C}$ overnight and was then centrifuged at $1300 \mathrm{~g}$ for $10 \mathrm{~min}$. Serum was collected and stored at $-20^{\circ} \mathrm{C}$ until analysis using indirect ELISA for the presence of anti-pFSH and anti-pLH antibodies.

Microtitre plates (96-well Maxisorp Immunoplate; Nalge Nunc International, Roskilde) were coated with $50 \mu \mathrm{l}$ per well pFSH or pLH diluted to $50 \mu \mathrm{g} \mathrm{pFSH} \mathrm{ml}{ }^{-1}$ or $2 \mu \mathrm{g} \mathrm{pLH} \mathrm{ml}{ }^{-1}$ in coating buffer ( 0.05 mol carbonate or bicarbonate buffer $\mathrm{I}^{-1}, \mathrm{pH}$ 9.6) and incubated overnight at $4{ }^{\circ} \mathrm{C}$. Plates were then washed with $0.05 \%(\mathrm{v} / \mathrm{v})$ Tween 20 (ICN Biomedicals Inc., Aurora, $\mathrm{OH}$ ) in PBS and blocked with $3 \%$ BSA (Trace) in PBS for $2 \mathrm{~h}$ at $37^{\circ} \mathrm{C}$. After washing again with PBS, $100 \mu$ l wallaby serum (diluted 1 in 100 with $1 \%$ BSA in PBS) was applied to triplicate wells and incubated overnight at $4{ }^{\circ} \mathrm{C}$. The plates were washed with PBS and $100 \mu \mathrm{l}$ polyclonal sheep antisera to wallaby immunoglobulin G (IgG; Kitchener et al., 2002) diluted 1 in 1000 was added for $1 \mathrm{~h}$ at $37^{\circ} \mathrm{C}$. Subsequently, 100 donkey anti-sheep IgG conjugated to alkaline phosphatase (Sigma, St Louis, MO) diluted 1 in 35000 was added for $30 \mathrm{~min}$ at $37^{\circ} \mathrm{C}$. Plates were washed and $100 \mu \mathrm{l}$ of the substrate $p$-nitrophenyl phosphate ( $p N P P$; Sigma) was added to each well. After $30 \mathrm{~min}$ at room temperature $\left(25^{\circ} \mathrm{C}\right), 20 \mu \mathrm{l} 2 \mathrm{~mol}$ sodium carbonate $\mathrm{I}^{-1}$ was added to each well to stop the reaction. The absorbance at $405 \mathrm{~nm}$ was determined with a Fluo-star Galaxy plate reader (BMG, Offenburg). The mean background value (without wallaby serum) was subtracted from each well before calculating the mean of triplicate values for each serum sample. Changes in absorbance values were used as an indirect indicator of relative antibody concentrations.

\section{Monitoring subsequent natural reproductive capacity}

The birth of pouch young was monitored for two breeding seasons after superovulation. The 15 treated wallabies were randomly allocated into two yards. Two adult males of proven reproductive ability were placed in each yard. Wallabies were caught at intervals of 3 weeks during the breeding season and their pouches were inspected for the presence of suckling young. A total of nine inspections were performed during the first breeding season after treatment. At each inspection any pouch young that were found were removed to induce a return to oestrus.

Wallabies were also caught three times during the second breeding season after treatment and inspected for the presence of pouch young.

\section{Statistical analysis}

The follicular response to repeated superovulation was analysed between groups by one-way ANOVA and within groups by paired Student's $t$ test. A chi-squared test was used to compare maturity of oocytes recovered from repeated superovulation treatment. Relative antigonadotrophin antibody concentrations were compared before and after superovulation using paired $t$ tests. A correlation coefficient was used to determine whether there was a relationship between number of follicles and anti-pFSH binding at the time of each superovulation. Breeding data were analysed by ANOVA. For all tests, a $P$ value $<0.05$ was considered significant.

\section{Results}

\section{Ovarian response to repeated superovulation}

There was no significant difference between groups in the number of large follicles $(2-5 \mathrm{~mm}$ in diameter) 
Table 1. Number of large (2-5 $\mathrm{mm}$ in diameter) follicles produced by the ovaries of the tammar wallaby (Macropus eugenii) in response to repeated superovulation with pig FSH and $\mathrm{LH}$

\begin{tabular}{lccc}
\hline & \multicolumn{3}{c}{ Number of large follicles present at: } \\
\cline { 2 - 4 } Group & Superovulation 1 & Superovulation 2 & Superovulation 3 \\
\hline S1 & $21.2 \pm 4.3^{*}$ & & \\
S2 & $23.8 \pm 3.4^{\mathrm{a}}$ & $18.0 \pm 6.5^{\mathrm{a} *}$ & \\
S3 & $25.0 \pm 8.0^{\mathrm{bc}}$ & $17.2 \pm 2.0^{\mathrm{b}}$ & $29.0 \pm 4.9^{\mathrm{c} *}$ \\
Total & $23.3 \pm 3.0$ & $17.6 \pm 3.2$ & $29.0 \pm 4.9$ \\
\hline
\end{tabular}

Values are mean $\pm \mathrm{SE}$.

S1: animals superovulated once; S2: animals superovulated twice; S3: animals superovulated three times.

*Number of follicles for final superovulation in each group did not differ significantly (one-way ANOVA, $P>0.05$ ).

${ }^{a b c}$ Values within the same row with different superscripts differ significantly (paired $t$ tests, $P<0.05$ ).

produced in response to the first $(21.2 \pm 4.3)$, second $(18.0 \pm 6.5)$ or third $(29.0 \pm 4.9)$ superovulation treatment (Table 1).

Within group S3, there was a significant difference in the number of follicles produced in response to the second and third superovulation treatments $(P<$ $0.05)$, but not between the first and second treatment or between the first and third treatment. There was no significant difference in the number of follicles between the first and second treatments in group S2 (Table 1).

\section{Oocyte collection rate}

A total of 547 oocytes was collected from 671 follicles using the surgical technique developed as part of this study. The mean oocyte collection rate (the number of oocytes recovered, divided by the number of follicles flushed) was $0.80 \pm 0.05$. The oocyte collection rate did not change significantly during the course of the study. A total of $18.2 \pm 2.0$ oocytes was recovered from each animal after each superovulation treatment. The number of oocytes recovered did not differ significantly among the first, second and third superovulation treatment either between or within groups (Table 2).

\section{Oocyte maturity}

Approximately $66 \%$ of all oocytes collected surgically after superovulation were mature, as assessed by the presence of a single polar body. This percentage is similar to that observed for oocytes collected by follicular aspiration of superovulated wallabies in other experiments (G. Magarey and K. Mate, unpublished). There was no significant difference in the proportion of mature oocytes recovered from the first, second or third superovulation treatment (Table 3 ).
Table 2. Number of oocytes collected surgically from the tammar wallaby (Macropus eugenii) after repeated superovulation with pig $\mathrm{FSH}$ and $\mathrm{LH}$

\begin{tabular}{lccc}
\hline & \multicolumn{3}{c}{ Number of oocytes recovered at: } \\
\cline { 2 - 4 } Group & Superovulation 1 & Superovulation 2 & Superovulation 3 \\
\hline S1 & $19.0 \pm 5.0^{*}$ & & \\
S2 & $17.6 \pm 4.7$ & $13.2 \pm 6.8^{*}$ & \\
S3 & $18.2 \pm 2.4$ & $15.2 \pm 2.8$ & $26.2 \pm 6.4^{*}$ \\
\hline
\end{tabular}

Values are mean \pm SE.

S1: animals superovulated once; S2: animals superovulated twice; S3: animals superovulated three times.

*Number of eggs for final superovulation in each group did not differ significantly (one-way ANOVA, $P>0.05$ ).

Table 3. Nuclear maturity of tammar wallaby (Macropus eugenii) oocytes collected surgically after repeated superovulation with pig $\mathrm{FSH}$ and $\mathrm{LH}$

\begin{tabular}{lccc}
\hline & $\begin{array}{c}\text { Number of } \\
\text { animals* }\end{array}$ & $\begin{array}{c}\text { Number of } \\
\text { oocytes }\end{array}$ & $\%$ PB1 \\
\hline Superovulation 1 & 13 & 203 & 67.5 \\
Superovulation 2 & 7 & 65 & 63.1 \\
Superovulation 3 & 4 & 86 & 64.0 \\
\hline
\end{tabular}

*Oocyte maturation data not collected for two animals at superovulation 1 ; three animals at superovulation 2 ; and one animal at superovulation 3 .

†Percentage of oocytes possessing a single polar body.

\section{Immune response against $\mathrm{pFSH}$ and $\mathrm{pLH}$}

A preliminary screening of sera from superovulated wallabies indicated that all had titres less than $10^{-3}$ and the pattern of immune response was similar for $\mathrm{pFSH}$ and pLH (Fig. 1a,b). Relative antibody concentrations were therefore analysed using a serum dilution of 1 in 100 . At this dilution, there was no significant correlation between FSH binding affinity at the time of superovulation and the number of follicles $(r=-0.365, P=0.061)$.

The mean relative $\mathrm{pFSH}$ and $\mathrm{pLH}$ antibody concentrations of sera from group S2 did not differ significantly from the naïve mean at 5-6 weeks after superovulation (Fig. 1a,b), but did differ at the same time point for groups $\mathrm{S} 1$ and $\mathrm{S} 3$. The mean relative $\mathrm{pFSH}$ and $\mathrm{pLH}$ antibody concentrations of sera from group S3 were not significantly different from the naïve mean at the time of the third superovulation treatment (Fig. 1a,b), but were significantly higher for $\mathrm{pFSH} 11-13$ weeks later.

\section{Morphological observations}

At the time of the second superovulation treatment, between one and four large cystic follicles $(6-8 \mathrm{~mm})$ were present on each ovary in five of 10 animals (two from group S2; three from group S3). All animals with cysts had a short interval (5-6 weeks) between first and 

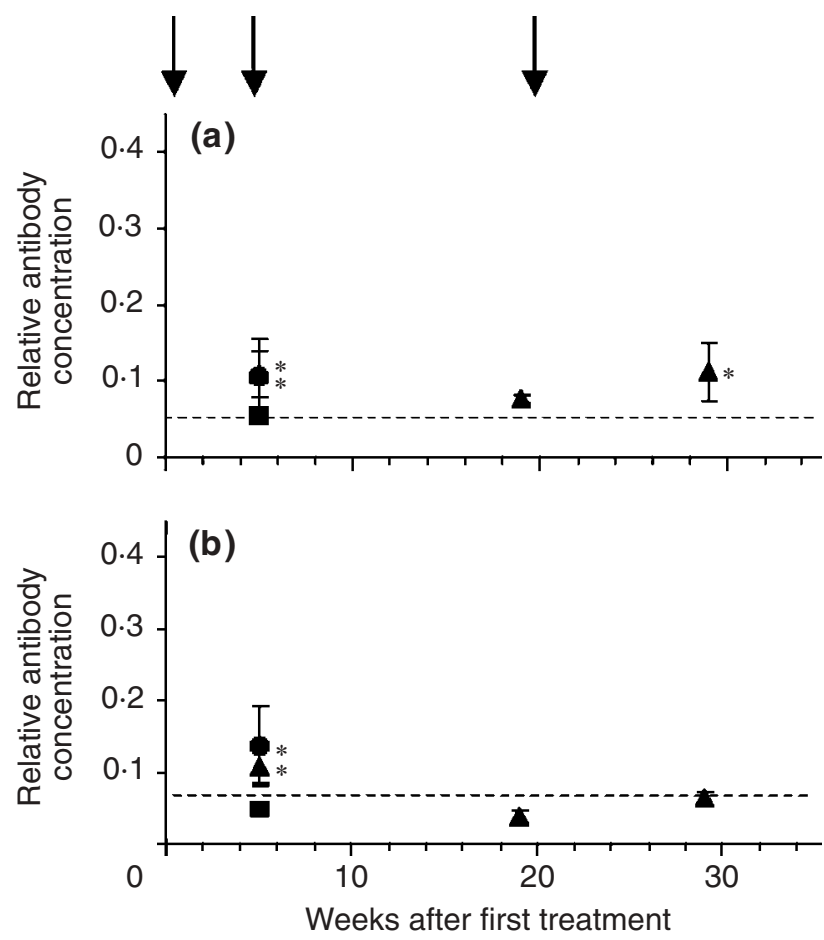

Fig. 1. The relative amount (absorbance at $450 \mathrm{~nm}$ ) of (a) antipig FSH antibodies and (b) anti-pig LH antibodies present in the serum of tammar wallabies (Macropus eugenii) superovulated once $(\boldsymbol{\bullet})$, twice $(\boldsymbol{\square})$ or three $(\mathbf{\Lambda})$ times. Arrows indicate the times of superovulation. The mean value of sera from all animals before treatment (naïve mean) is shown as a dashed line. *Significant difference from pre-treatment values (paired $t$ tests, $P<0.05$ ).

second treatment. There were no cysts at the time of the third superovulation treatment. Mild adhesions were observed between the fimbriae of the oviducts and the associated ovary in three of 10 animals at the time of the second superovulation. At the third superovulation, adhesions were observed in four of five animals. The most severe case involved adhesion of approximately $70 \%$ of the oviductal fimbria to one ovary; however, the extent of adhesions was mild in most cases.

\section{Effects on fertility}

There was no significant difference between groups in the number of animals that produced pouch young in the breeding season following superovulation and surgical oocyte collection. All five animals treated once (group S1) gave birth to young (Table 4). Four of five animals treated twice (group S2) or three times (group S3) produced young during the same period. The total number of young produced by individual animals during the breeding season did not differ between groups S1 and S2, or between groups S2 and S3. However, animals in group S3 produced significantly fewer young than did those in S1 (Table 4). The animal in group S2 that did
Table 4. Breeding activity of tammar wallabies (Macropus eugenii) during the breeding season after repeated superovulation with pig $\mathrm{FSH}$ and $\mathrm{LH}$

\begin{tabular}{lcc}
\hline Group & $\begin{array}{c}\text { Number of animals } \\
\text { that produced young }\end{array}$ & $\begin{array}{c}\text { Number of young } \\
\text { per animal }\end{array}$ \\
\hline S1 & 5 of 5 & $3.2 \pm 0.4^{\mathrm{a}}$ \\
S2 & 4 of 5 & $1.6 \pm 0.5$ \\
S3 & 4 of 5 & $1.0 \pm 0.3^{\mathrm{a}}$ \\
\hline
\end{tabular}

S1: animals superovulated once; S2: animals superovulated twice; S3: animals superovulated three times.

a Values differ significantly (one-way ANOVA, $P<0.05$ ).

not produce a pouch young died towards the end of the breeding season.

During the second season after superovulation, all animals in group S1 (five of five) and all remaining animals in group S2 (four of four) produced young. The wallaby in group S3 that did not produce a young in the first breeding season after treatment was one of four animals (out of five) in S3 that produced a young during the second breeding season.

\section{Discussion}

This study has demonstrated the feasibility of repeated superovulation and surgical oocyte collection in a model marsupial. Tammar wallabies responded to repeated pLH or $\mathrm{pFSH}$ superovulation, producing a mean of 22 follicles per treatment with no decline in ovarian response after three stimulation cycles.

Approximately 18 oocytes were retrieved surgically per animal per stimulation. Overall the oocyte collection rate was $80 \%$, which is comparable with that reported for other species using similar follicle aspiration techniques, for example 86\% for cat (Swanson et al., 1996), 69\% for goats (Graff et al., 1999), and 43\% for red deer (Bainbridge et al., 1999). It should be noted that in preliminary trials tammar wallaby eggs were susceptible to considerable damage during collection if aspiration pressures over $100 \mathrm{~mm} \mathrm{Hg}$ were used, perhaps due to their relatively large size.

Detectable concentrations of antibodies were produced against the pig gonadotrophins (pFSH and $\mathrm{pLH}$ ) used for superovulation of tammar wallabies. The relative anti-gonadotrophin antibody concentrations in wallaby serum were low but comparable to that found to affect ovarian response to superovulation in eutherian species. End-point titres for anti-gonadotrophin immunoglobulins ranged from 1 in 4 to 1 in 65 in primates (Bavister et al., 1986), and from 1 in 100 to 1 in 1600 in cats (Swanson et al., 1995, 1996) after superovulation with exogenous gonadotrophins. This immune response was sufficient to induce an immunologically mediated refractoriness to ovarian stimulation (Bavister et al., 1986; Swanson et al., 1995, 1996). The anti-gonadotrophin antibodies 
generated by tammar wallabies in the present study did not cause a significant decrease in the number of follicles or in oocyte maturity over the course of the study.

Although there was no overall decline in ovarian response to superovulation after three treatments, in group S3 there were significantly fewer follicles induced by the second stimulation compared with the third, although neither differed significantly from the first treatment. The slightly decreased ovarian response to the second treatment may have been related to the relatively short interval (5-6 weeks) since the first treatment, compared with the longer interval between the second and third treatments (13-17 weeks). Swanson et al. (1996) also reported that longer intervals between repeated gonadotrophin stimulations were beneficial for maintenance of ovarian responsiveness in cats. This effect was associated with a decline in anti-gonadotrophin immunoglobulins (Swanson et al., 1996), which may also have been a factor in the present study, as FSH relative antibody concentrations were highest at the time of the second treatment. It is also possible that 5-6 weeks may be insufficient time for full replenishment of the pool of follicles receptive to stimulation. Studies of ovarian development in the tammar wallaby (Alcorn, 1975) and brushtail possum (Frankenberg et al., 1996) indicate that development of follicles from type 4 (two layers of granulosa cells) to type 6 (early antrum formation) requires at least 30-35 days. Consequently, there may have been fewer follicles at the correct developmental stage for recruitment with $\mathrm{pFSH}$ at the time of the second treatment.

The presence of large cystic follicles in three animals in group S3 at the time of the second treatment may also have contributed to the decreased ovarian response. Other authors have reported ovarian cysts or 'highly stimulated' ovaries after $\mathrm{pFSH}$ or $\mathrm{pLH}$ treatment in marsupials (Molinia et al., 1998b; Jungnickel and Hinds, 2000). A high proportion of these large follicles fail to ovulate, show signs of premature luteinization and contain trapped oocytes (Jungnickel and Hinds, 2000), indicating that the doses of pFSH or pLH currently used for superovulation in the tammar wallaby are not optimal. It is therefore likely that the cysts observed in the present study developed as a result of the first superovulation treatment and had an inhibitory effect on follicular development during the second stimulation cycle. Modification of the oocyte collection procedure to include the puncturing of small 0.5$2.0 \mathrm{~mm}$ non-aspirated follicles may have prevented cyst formation as none were observed at the third treatment. Alternatively, the longer interval between the second and third superovulations may have been sufficient time for regression of any cysts that resulted from the second treatment.

Although 14 of 15 animals that underwent superovulation and surgical oocyte collection demonstrated subsequent natural breeding in the two seasons after treatment, animals treated once only were more productive than those treated three times. The development of adhesions from repeated surgical oocyte collections may have contributed to lower subsequent breeding activity due to impaired oocyte collection or transport by the oviduct(s). Adhesions resulting from repeated surgical collection (via laparotomy) of embryos reduce fertility in ewes (Torres and Sevellec, 1987). Similar studies in sheep and cattle using laparoscopic or ultrasoundguided methods of oocyte or embryo collection reported few or no adhesions after repeated treatment and no decline in reproductive potential (Broadbent et al., 1997; Stangl et al., 1999). The development of a method for laparoscopic collection of oocytes may therefore be warranted, particularly for repeated collections from valuable marsupials, in order to reduce the risk of adhesions and subsequent effects on fertility.

It is essential that the highest standards of animal husbandry are maintained during superovulation and oocyte collection. During the course of this trial four animals presented with signs of respiratory disease and pulmonary congestion leading to death 1-4 weeks after a single treatment (results not presented). Although a definitive diagnosis was not identified, exposure to winter conditions during treatment may have contributed to reduced immune function leading to onset of disease. Accordingly, as the procedure itself is potentially stressful (involving repeated capture, anaesthesia and surgical recovery), housing of animals in a controlled indoor environment in order to reduce additional environmental stresses may be beneficial. The interval between successive treatments should also be considered, to allow a sufficient period for recovery and thereby reduce the chance of stress-induced disease.

In conclusion, the tammar wallaby ovary responds to repeated $\mathrm{pFSH}$ or $\mathrm{pLH}$ superovulation. In the present study, there was no significant decline in ovarian response after three superovulation and surgical oocyte collection treatments and all animals demonstrated subsequent natural fertility. Combined with other assisted reproductive technologies, repeated superovulation and surgical oocyte collection can contribute to continued research into marsupial gamete biology and potentially to the increased productivity of rare or valuable marsupials in captivity.

The authors thank R. Claassens and staff at the Macquarie University Fauna Park for care of the animals, Vetrepharm for the generous donation of pig FSH, and F Molinia for comments on the manuscript. This work was supported by the Australian Government's Cooperative Research Centres Program. G. M. Magarey was the recipient of a Macquarie University Postgraduate Research Award.

\section{References}

Alcorn GT (1975) Development of the Ovary and Urogenital Ducts in the Tammar Wallaby, Macropus eugenii (Desmarest 1817) PhD Thesis. School of Biological Sciences, Macquarie University, NSW Australia 
Bainbridge DRJ, Catt SL, Evans G and Jabbour HN (1999) Successful in vitro fertilization of in vivo matured oocytes aspirated laparoscopically from red deer hinds (Cervus elaphus) Theriogenology 51 891-898

Bavister BD, Boatman DE, Collins K, Dierschke DJ and Eislele SG (1984) Birth of rhesus monkey infant after in vitro fertilization and non-surgical embryo transfer Proceedings National Academy of Sciences USA 81 2218-2222

Bavister BD, Dees C and Schultz RD (1986) Refractoriness of rhesus monkeys to repeated ovarian stimulation by exogenous gonadotropins is caused by non-precipitating antibodies American Journal of Reproductive Immunology 11 11-16

Broadbent PJ, Dolman DF, Watt RG, Smith AK and Franklin MF (1997) Effect of frequency of follicle aspiration on oocyte yield and subsequent superovulatory response in cattle Theriogenology 47 1027-1040

Frankenberg S, Newell G and Selwood L (1996) A light microscopic study of oogenesis in the brushtail possum, Trichosurus vulpecula. Reproduction, Fertility and Development 8 541-546

Goodrowe KL, Wall RJ, O'Brien SJ, Schmidt PM and Wildt DE (1988) Developmental competence of domestic cat follicular oocytes after fertilization in vitro. Biology of Reproduction 39 355-372

Graff KJ, Meintjes M, Dyer VW, Paul JB, Denniston RS, Ziomek C and Godke RA (1999) Transvaginal ultrasound-guided oocyte retrieval following FSH stimulation of domestic goats Theriogenology 51 10991119

Hickford DE, Merry NE, Johnson MH and Selwood L (2001) Induced ovulation, mating success and embryonic development in the stripefaced dunnart, Sminthopsis macroura. Reproduction 122 777-783

Hinds LA, Poole WE, Tyndale-Biscoe $\mathrm{CH}$, van Oorschot RAH and Cooper DW (1990) Reproductive biology and the potential for genetic studies in the tammar wallaby, Macropus eugenii. Australian Journal of Zoology 37 223-234

Holt WV and Pickard AR (1999) Role of reproductive technologies and genetic resource banks in animal conservation Reviews of Reproduction 4 143-150

Iliff SA, Molskness TA and Stouffer RL (1995) Anti-human gonadotropin antibodies generated during in vitro fertilization (IVF)-related cycles - effect on fertility of rhesus macaques Journal of Medical Primatology 24 7-11

Johnston SD and Holt WV (2001) Germplasm conservation in marsupials. In Cryobanking the Genetic Resource: Wildlife Conservation for the Future? pp 201-225 Eds PF Watson and WV Holt. Taylor and Francis, London

Jungnickel MK and Hinds LA (2000) Hormonal profiles in the tammar wallaby, Macropus eugenii, following $\mathrm{FSH} / \mathrm{LH}$ superovulation Reproduction, Fertility and Development 12 457-464

Kitchener AL, Edds LM, Molinia FC and Kay DJ (2002) Porcine zonae pellucidae immunization of tammar wallabies (Macropus eugenii): fertility and immune responses Reproduction, Fertility and Development 14 215-223

Kuehl TJ and Dukelow WR (1979) Maturation and in vitro fertilization of follicular oocytes of the squirrel monkey (Saimari sciureus) Biology of Reproduction 21 545-556

Kuhholzer B, Muller S, Treuer A, Seregi J, Besenfelder U and Brem G (1997) Repeated endoscopic ovum pick-up in hormonally untreated ewes: a new technique Theriogenology 48 545-550

Loskutoff NM, Bartels P, Meintjes M, Godke RA and Schiewe MC (1995) Assisted reproductive technology in non-domestic ungulates - a model approach to preserving and managing genetic diversity Theriogenology 43 3-12

Mate KE and Rodger JC (1993) In vitro maturation of oocytes from a marsupial, the tammar wallaby (Macropus eugenii) Molecular Reproduction and Development 34 329-336

Mate KE, Giles I and Rodger JC (1992) Evidence that cortical granule formation is a periovulatory event in marsupials Journal of Reproduction and Fertility 95 719-728

Mate KE, Gentle RL, Fletcher TP and Rodger JC (1999) Australian marsupials. In UFAW Handbook on the Care and Management of Laboratory Animals 7th Edn pp 210-234 Ed. TB Poole. Blackwell Press, London

Miller AM, Roelke ME, Goodrowe KL, Howard JG and Wildt DE (1990)
Oocyte recovery, maturation and fertilization in vitro in the puma (Felis concolor) Journal of Reproduction and Fertility 88 249-258

Molinia FC and Rodger JC (1996) Pellet-freezing spermatozoa of two marsupials: the tammar wallaby, Macroups eugenii and the brushtail possum, Trichosurus vulpecula. Reproduction, Fertility and Development 8 681-684

Molinia FC, Gibson RJ, Smedley MA and Rodger JC (1998a) Further observations of the ovarian response of the tammar wallaby (Macropus eugenii) to exogenous gonadotrophins: an improved method for superovulation using FSH/LH Animal Reproduction Science 53 253-263

Molinia FC, Gibson RJ, Brown AM, Glazier AM and Rodger JC (1998b) Successful fertilization after superovulation and laparoscopic intrauterine insemination of the brushtail possum, Trichosurus vulpecula, and tammar wallaby, Macropus eugenii. Journal of Reproduction and Fertility 113 9-17

Pieterse MC, Kappen KA, Kruip TAM and Taverne MAM (1988) Aspiration of bovine oocytes during transvaginal ultrasound scanning of the ovaries Theriogenology 30 751-762

Remy B, Baril G, Vallet JC, Dufour R, Chouvet C, Saumande J, Chupin D and Beckers JF (1991) Are antibodies responsible for a decreased superovulatory response in goats which have been treated repeatedly with porcine follicle-stimulating hormone? Theriogenology 36 389-399

Rodger JC (1990) Prospects for the artificial manipulation of marsupial reproduction and its application in research and conservation Australian Journal of Zoology 37 249-258

Rodger JC and Mate KE (1988) A PMSG/GnRH method for the superovulation of the monovulatory brush-tailed possum (Trichosurus vulpecula) Journal of Reproduction and Fertility 83 885-891

Rodger JC, Breed WG and Bennett JH (1992) Gonadotrophin-induced oestrus and ovulation in the polyovulatory marsupial Sminthopsis crassicaudata. Reproduction, Fertility and Development 4 145-152

Roy F, Maurel MC, Combes B, Vaiman D, Cribiu EP, Lantier I, Pobel T, Deletang F, Combarnous Y and Guillou F (1999) The negative effect of repeated equine chorionic gonadotrophin treatment on subsequent fertility in alpine goats is due to a humoral immune response involving the major histocompatibility complex Biology of Reproduction 60 805813

Sauer MV (1996) Laparoscopy after multiple follicle aspirations fails to demonstrate pathology in oocyte donors Journal of Assisted Reproduction and Genetics 13 450-452

Stangl M, Kuhholzer B, Besenfelder U and Brem G (1999) Repeated endoscopic ovum pick-up in sheep Theriogenology 52 709-716

Swanson WF, Horohov DW and Godke RA (1995) Production of exogenous gonadotrophin-neutralizing immunoglobulins in cats after repeated eCG-hCG treatment and relevance for assisted reproduction in felids Journal of Reproduction and Fertility 105 35-41

Swanson WF, Roth TL, Graham K, Horohov DW and Godke RA (1996) Kinetics of the humoral immune response to multiple treatments with exogenous gonadotropins and relation to ovarian responsiveness in domestic cats American Journal of Veterinary Research 57 302-307

Taggart DA, Leigh CM, Steele VR, Breed WG, Temple-Smith PD and Phelan J (1996) Effect of cooling and cryopreservation on sperm motility and morphology of several species of marsupial Reproduction, Fertility and Development 8 673-679

Tervit HR (1996) Laparoscopy/laparotomy oocyte recovery and juvenile breeding Animal Reproduction Science 42 227-238

Torres S and Sevellec C (1987) Repeated superovulation and sugical recovery of embryos in the ewe Reproduction, Nutrition, Development 27 859-863

Wildt DE, Ellis S and Howard JG (2001) Linkage of reproductive sciences: from 'quick fix' to 'integrated' conservation Journal of Reproduction and Fertility Supplement 57 295-307

Received 23 October 2002

First decision 5 December 2002.

Revised manuscript received 17 December 2002.

Accepted 20 January 2003. 